\author{
Oksana Makota and Yuriy Trach
}

\title{
THE STUDIES ON COMPLEX FORMATION OF METAL BORIDES IN THE REACTION SYSTEM OF EPOXIDATION OF 1-OCTENE WITH TERT-BUTYL HYDROPEROXIDE BY IR SPECTROSCOPY
}

Received: M arch 26, 2007

\author{
Lviv Polytechnic National University, \\ 12 S.Bandera str., 79013 Lviv, Ukraine \\ yu.trach@polynet.Iviv.ua
}

\begin{abstract}
The complex formation of molybdenum and vanadium borides in the reaction system of 1-octene epoxidation with tert-butyl hydroperoxide by infrared spectroscopic analysis was studied. It was shown that 1-octene forms complex with metal moiety in the case of molybdenum boride and with boron moiety in the case of vanadium boride.
\end{abstract}

Keywords: infrared spectroscopy catalyst, epoxidation, olefin, hydroperoxide

\section{Introduction}

Epoxides are an important class of organic compounds which are widely used as intermediate reagents in the organic synthesis of various oxygenated compounds, in the production of polyurethane resins, surfactants, polymers, biologically active compounds, etc. [1-4]. One of the effective methods of the epoxides synthesis is catalytic epoxidation reaction of olefin with hydroperoxides.

The formation of two types of double complexes is possible in the reaction system of hydroperoxide epoxidation, which contains hydroperoxide, olefin and catalyst - hydroperoxide-catalyst and olefin-catalyst complexes. It was shown by the kinetic method of investigation in [5-8], that a primary complex which is responsible for the formation of epoxide is olefin-catalyst complex. The equilibrium exists between the complexes of hydroperoxide-catalyst and olefin-catalyst:

$$
\begin{aligned}
& \text { Hydroperoxide-Catalyst }+ \text { Olefin } \rightleftarrows \\
& \rightleftarrows \text { Olefin-Catalyst }+ \text { Hydroperoxide }
\end{aligned}
$$

The selectivity of epoxide formation is higher when this equilibrium is more accented toward formation of olefin-catalyst complex.

In this work, using infrared (IR) spectroscopy, we investigated the complex formation processes which occur on the surface of $\mathrm{MoB}$ and $\mathrm{VB}$ heterogeneous catalysts at their interaction with the components of 1-octene epoxidation with tert-butyl hydroperoxide (TBHP) reaction system for confirmation of the conclusions received by the kinetic way.

\section{Experimental}

Commercial 1-octene of pure grade was additionally purified by distillation. TBHP was synthesized by the procedure described in [5]. The catalysts were commercial chemicals of a chemically pure grade. Chlorbenzene of reagent pure grade used as a solvent was additionally dried and distilled. The epoxidation process was carried out in an argon atmosphere in a thermostated glass reactor fitted with a reflux condenser and a magnetic stirrer as well as constant temperature jacket to keep the temperature constant within $\pm 0.1 \mathrm{~K}$.

The reaction mixture was analyzed using a Tsvet 100 chromatograph with $3 \mathrm{~m}$ long column packed with $10 \%$ Apieson L on Chromaton N-AW. The column temperature was $410 \mathrm{~K}$ and the carrier gas (hydrogen) flow rate was $3.6 \mathrm{l} / \mathrm{h}$. The hydroperoxide concentration was determined by iodometric titration.

The IR spectra of initial catalysts as well as the catalysts after their interaction with 1-octene or TBHP were recorded by SPECORD- 80 spectrometer in 4000 $400 \mathrm{~cm}^{-1}$ range using pressed $\mathrm{KBr}$ pellets. The catalyst samples treated by reagents were prepared in such a way: the catalyst was added to the solution of 1-octene or TBHP (the concentrations of 1-octene and TBHP were equal to the concentrations of these compounds in the epoxidation reaction mixture). This mixture was stirred for the period which was equal to the time of the catalytic epoxidation reaction. Then the catalyst was separated from this mixture, pressed with $\mathrm{KBr}$ and IR spectra were recorded. 


\section{Results and Discussion}

In Fig. 1 the kinetic curves of TBHP consumption and 1,2-epoxyoctane accumulation in the process of 1-octene epoxidation with TBHP in the presence of MoB and VB are shown. One can see, that the amount of epoxide which is formed at the identical TBHP consumption is almost 3 times less in the case of VB than that in the case of MoB. It indicates a considerably greater contribution of unproductive decomposition process of TBHP in comparison with the consumption for epoxide formation in the case of VB. In accordance with [5], this effect must be connected with the much greater stability of hydroperoxide-catalyst complex in comparison with olefincatalyst complex in VB case.

The IR spectra of initial molybdenum and vanadium borides as well as the spectra of these catalysts after their interaction with 1-octene and TBHP are shown in Figs. 2 and 3. One can see that initial MoB (Fig. 2, spectrum 3) and VB (Fig. 3, spectrum 3) spectra have intensive absorption bands at $717,1428,3217,3399 \mathrm{~cm}^{-1}$ and at $1195,1421,1629,3231,3410 \mathrm{~cm}^{-1}$ respectively. The intensity and absorption frequency of these bands are changing after interaction of the catalyst with components of the reaction system.

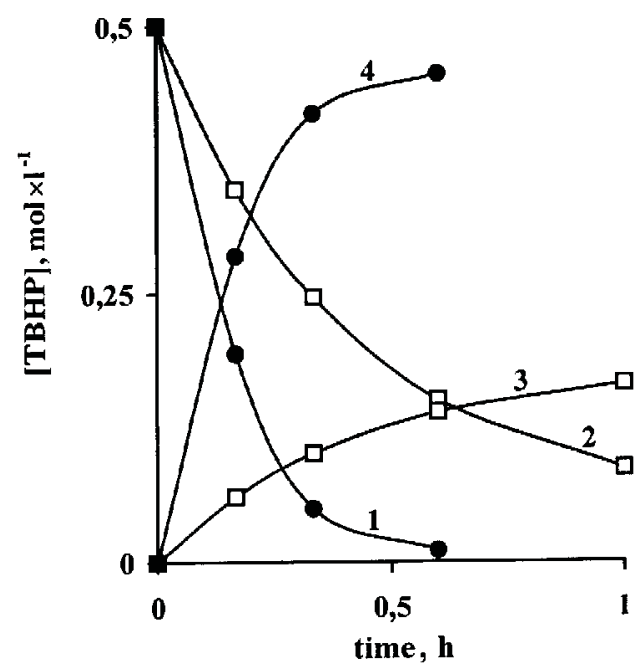

Fig. 1. TBHP $(1,2)$ and epoxyoctane $(\mathrm{EP})(3,4)$ concentrations as the functions of reaction time in the epoxidation reaction of 1-octene with TBHP in the presence of $\mathrm{MoB}(1,4)$ and $\mathrm{VB}(2,3)$. Reaction conditions: $\mathrm{T}=363 \mathrm{~K}$, octene $2.5 \mathrm{~mol} / \mathrm{l}$, catalyst $10 \mathrm{~g} / \mathrm{l}$.

The IR spectra of initial VB after itsinteraction with TBHP (Fig. 3, spectrum 1) and 1-octene (Fig. 3, spectrum 2) are changing and become similar to each other. They contain absorption bands at 1195, 1448 (with 1-octene), 1456 (with TBHP) and $3212 \mathrm{~cm}^{1}$. The comparison of VB spectra 3 with 1 and 2 suggests that intensity of absorption band at 1195 increases and the band at 1421 (spectrum 3) shifts to 1448 (spectrum 2) and 1456 (spectrum 1). The band intensity at 3410 (spectrum 3) decreases and this band is overlapped by the band at 3212 (spectra 1 and 2). The band at 3212 shifts by $19 \mathrm{~cm}^{-1}$ in comparison with this band in spectrum 3 .

The IR spectra of MoB after their interaction with TBHP (Fig. 2, spectrum 1) and 1-octene (Fig. 2, spectrum 2) are changing too. But in contrast to VB spectra, MoB spectra 1 and 2 are differed considerably. After their interaction with 1-octene (Fig. 2, spectrum 2) MoB spectrum contains absorption bands at 1385, 1637 and $3426 \mathrm{~cm}^{-1}$. The band at 3217 in spectrum 3 overlaps that in spectrum 2 by a stronger band at $3426 \mathrm{~cm}^{-1}$. Band at 1637 appears in spectrum 2 together with band at 3426, but it is very weak in spectrum 3 .

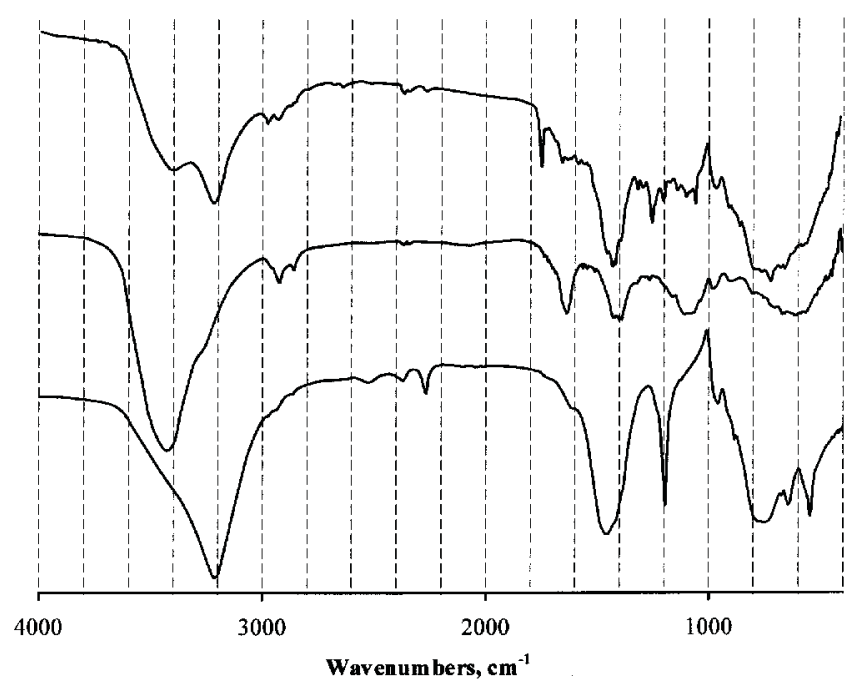

Fig. 2. IR spectra of the initial $\mathrm{MoB}(3)$ and $\mathrm{MoB}$ after their interaction with TBHP (1) and 1-octene (2).

After the interaction with TBHP (Fig. 2, spectrum 1) absorption bands at 1195, 1456 and $3214 \mathrm{~cm}^{-1}$ are observed in MoB spectrum. In comparison with spectrum of the initial MoB (spectrum 3) the band intensity at 1195 appears in spectrum 1 which is also presented in VB spectra too, the band at $3214 \mathrm{~cm}^{-1}$ increases and overlaps the band at 3399 which is in spectrum 3. In comparison with spectrum 3 the band intensity at $1456 \mathrm{~cm}^{-1}$ increases with the increase of the band intensity at $3214 \mathrm{~cm}^{-1}$.

From the spectra in Figs. 2 and 3 one can see two groups of mutual connection absorption bands at about 3400 and 1640 as well as at 3220 and $1400 \mathrm{~cm}^{-1}$. Increasing intensity of one of the bands in the group at higher wavenumbers at about 3400 or 3220 results in increasing intensity of respective lower wavenumbers at about 1640 or $1400 \mathrm{~cm}^{-1}$. This fact indicates the presence of two centres on MoB and VB surfaces which can react with reagents of epoxidation reaction system. The centre 
which has absorbtion band at about 3220 and $1400 \mathrm{~cm}^{-1}$ reacts in case of MoB with TBHP interaction, while the centre which has absorption bands at about 3400 and $1640 \mathrm{~cm}^{-1}$ reacts with 1-octene. Only one centre which absorbs at about 3220 and $1400 \mathrm{~cm}^{-1}$ reacts in case of $\mathrm{VB}$ with TBHP and 1-octene interaction, as it can be seen from the similar VB spectra after its interaction with TBHP and 1-octene (Fig. 3, spectra 1 and 2).

The wide absorption bands at about 3400 and $3220 \mathrm{~cm}^{-1}$ are assigned to stretching vibrations of $-\mathrm{OH}$ bonds and bands at about 1640 and $1400 \mathrm{~cm}^{-1}$ - to the deformation vibrations of $-\mathrm{OH}$ bonds [9]. The peak at about $1400 \mathrm{~cm}^{-1}$ may be assigned to stretching vibrations of B-O bond [10] and the corresponding band at about 3220 may be assigned to the stretching vibrations of $-\mathrm{OH}$ group bonded with boron.

The second group of the absorption bands at around 3400 and $1640 \mathrm{~cm}^{-1}$ can be assigned to the absorption of $-\mathrm{OH}$ group bonded with the metal atom of boride. The comparison of obtained results of epoxidation process presented in Fig. 1 with the results of spectra analysis suggests that the high selectivity of the epoxidation process in the presence of MoB may be connected with the formation of olefin-catalyst complex on the surface of this boride. In case of VB olefin interacts mainly with boron moiety, mainly results in nonproductive decomposition of TBHP.

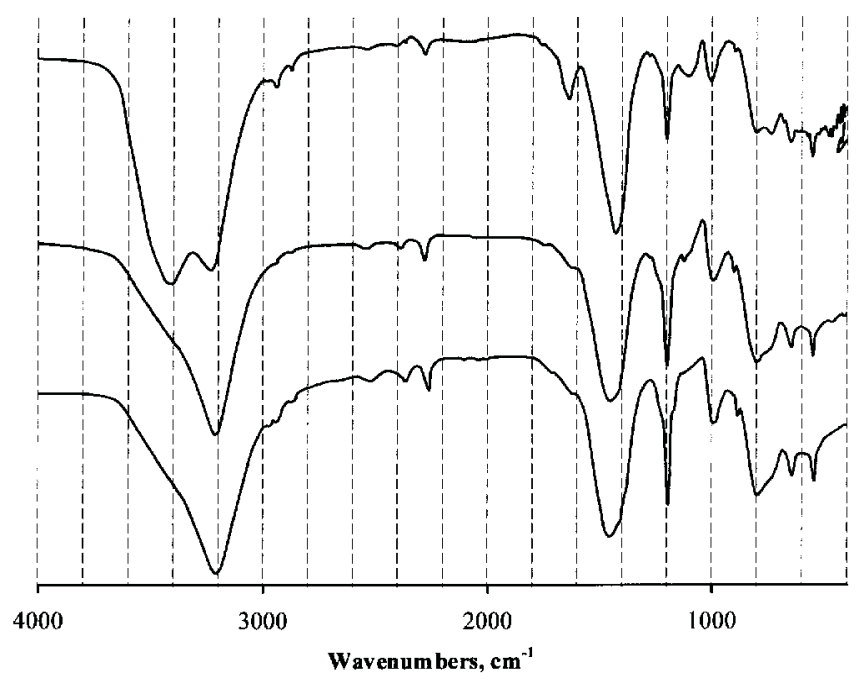

Fig. 3. IR spectra of the initial VB (3) and VB after their interaction with TBHP (1) and 1-octene (2).

\section{Conclusions}

Thus, the obtained results can confirm the preliminary conclusion based on kinetic results that the epoxidation process proceeds through the primary formation of the olefin-catalyst complex.

The obtained spectrum data indicate that olefin must form the complex with the metal moiety of metal compound for the selective convertion to epoxide,.

Further investigations will be focused on studying of complex formation on the surface of other catalysts in the hydroperoxide epoxidation reaction system by means of infrared spectroscopy.

\section{References}

[1] Yudin A.: Aziridines and epoxides in organic synthesis. Wiley-VCH, Weinheim, Germany 2006.

[2] Weissermel K. and Arpe H.-J.: Industrial organic chemistry, Wiley-VCH, Weinheim, Germany 2003.

[3] Cornils B. and Herrmann W.A. (eds): Applied homogeneous catalysis with organometallic compounds. Wiley-VCH, Weinheim, Germany 2002, V. 1.

[4] Adam W. (ed.): Peroxide Chemistry. Mechanistic and preparative aspects of oxygen transfer. Wiley-VCH, Weinheim, Germany 2000.

[5] Trach Yu., Makota O., Nikipanchuk M., Pyrig I. and Makitra R.: Petroleum Chemistry 2003, 43, 424.

[6] Trach Yu. and Makota O.: Petroleum Chemistry 2004, 44, 48.

[7] Trach Yu. and Makota O.: Petroleum Chemistry 2005, 45, 327.

[8] Trach Yu., Schulze B., Makota O. and Bulgakova L.: J. Molecular Catalysis A: Chemical 2006, 258, 292.

[9] Sian T.S. and Reddy G.B.: Solid state ionics 2004, 167, 399. [10] Ardelean I., Toderas M. and Pascuta P.: Modern physics letters B, 2003, 17, 1175 .

\section{ВИВЧЕННЯ КОМПЛЕКСОУТВОРЕННЯ БОРИДІВ МЕТАЛІВ У РЕАКЦЙНІЙ СИСТЕМІ ЕПОКСИДУВАННЯ ОКТЕНУ-1 ГІДРОПЕРОКСИДОМ ТРЕТБУТИЛУ МЕТОДОМ ІЧ СПЕКТРОСКОПІЇ}

Анотація. Вивчено комплексоутворення боридів молібдену і ванадію в реакиійній системі епоксидування октену-1 гідропероксидом трет-бутилу методом інфрачервоної спектроскопії. Показано, що октен-1 утворює комплекс з металевою складовою у випадку бориду молібдену $i$ з боридною складовою у випадку бориду ванадію.

Ключові слова: інфрачервона спектроскопія, каталізатор, епоксидування, олефін, гідропероксид 
